\title{
Factors Determining Thyroid Status in Pregnant Women in Bulgaria
}

\author{
Anna-Maria Borissova ${ }^{1,2}$, Boyana Trifonova ${ }^{1,2,}$, Lilia Dakovska ${ }^{1}$, Eugenia Michaylova ${ }^{1}$, \\ Mircho Vukov ${ }^{1}$ \\ ${ }^{1}$ Clinic of Endocrinology, University Hospital Sofiamed, Sofia, Bulgaria \\ ${ }^{2}$ Faculty of Medicine, Sofia University St. Kliment Ohridski, Sofia, Bulgaria
}

Email address:

boianatri@abv.bg (B. Trifonova)

*Corresponding author

\section{To cite this article:}

Anna-Maria Borissova, Boyana Trifonova, Lilia Dakovska, Eugenia Michaylova, Mircho Vukov. Factors Determining Thyroid Status in Pregnant Women in Bulgaria. International Journal of Diabetes and Endocrinology. Vol. 5, No. 4, 2020, pp. 89-95. doi: $10.11648 /$ j.ijde.20200504.17

Received: November 23, 2020; Accepted: December 8, 2020; Published: December 31, 2020

\begin{abstract}
Thyroid dysfunction occurs in 5-18\% of pregnant women and is associated with a higher risk of various gynecological and obstetric complications and these differences are due to the specific characteristic of the study population. The aim of the present study is to analyze the population of pregnant women in Bulgaria regarding the main parameters that are relevant to their thyroid status - age, sequence of pregnancy, reproductive problems, family history of thyroid disease, body mass index. Material: We studied 547 pregnant women, mean age $30 \pm 5$ years. The study was conducted as a cross-sectional multicenter population-based in 10 regions of Bulgaria or a total of 84 settlements. Methods: An individual Questionnaire was completed, determined in a central laboratory with ECLIA method TSH, FT4, TPOAb and ultrasound examination of the cervical region was conducted. Statistical processing of the material was performed using the standard SPSS 13.0 for Windows. Results: TSH levels are negatively correlated with age, $\mathrm{P}<0.07$. The thyroid volume for the group of women with first pregnancy $(\mathrm{n}-245,44.8 \%)$ is $8.67 \pm 2.23 \mathrm{~mL}$, median $8.35 \mathrm{~mL}$, and the thyroid volume in the remaining $302(55.2 \%)$ women with another pregnancy is $9.15 \pm 2.85$ $\mathrm{mL}$, median $8.96 \mathrm{~mL}(\mathrm{P}<0.01)$. Reproductive problems were reported in $119(21.8 \%)$ pregnant women, but the correlation with TSH levels was weak, $\mathrm{P}<0.009$. In $25 \%$ of women with family history of thyroid pathology there are abnormalities in thyroid function (in $96.4 \%$ hypothyroidism and in 3.6\% hyperthyroidism). While in euthyroid pregnant women previous obesity was present in 8.6\% (30/350), in hypothyroid pregnant women it was found in $12.7 \%(14 / 110), \mathrm{P}<0.035$. In other words, BMI before pregnancy is a significant predictor of hypothyroidism, proven during pregnancy. Conclusion: The preliminary in-depth study and presentation of the characteristics of the studied Bulgarian population of pregnant women is the basis for a proper assessment of the condition of the thyroid gland.
\end{abstract}

Keywords: Thyroid Status, Age, Sequence of Pregnancy, Reproductive Problems, Family History, Body Mass Index

\section{Introduction}

The prevalence of thyroid disorders in group of 20-45year-old women has been estimated to be between 5 to $7 \%$ for subclinical hypothyroidism (SCHT), 2 to $4.5 \%$ for clinical hypothyroidism (CHT), 0.5 to $1 \%$ for hyperthyroidism and 5 to $10 \%$ for thyroid autoimmunity [1].

Thyroid dysfunction occurs in 5-18\% of pregnant women and is associated with a higher risk of various gynecological and obstetric complications [2-5]. Pregnancy places additional demands on the thyroid gland and in about $5 \%$ of women who have checked their thyroid function during pregnancy, subclinical hypothyroidism will be found, which is unfavorable for the outcome of pregnancy and for the offspring [6]. Abalovich M. et al. found that 34\% of women with hypothyroidism became pregnant without treatment with Levothyroxine, with $11 \%$ having CHT and $89 \%$ SCHT [7]. SCHT occurs in $2-2.5 \%$ of pregnant women according to Lazarus $\mathrm{JH}$, while in Belgium they report a frequency of $6.8 \%$ and in northern Spain - 13.7\% [8-10]. At the same time, Alkafajei A. et al. (2012) conducted a cross-sectional study 
and found that the prevalence of SCHT was 20.8\% according to laboratory data and internationally accepted criteria [11]. Various studies have demonstrated that when using a fixed upper reference limit of TSH, about $8-28 \%$ of pregnant women show high levels of this hormone $[12,13]$. CHT is much less common in pregnant women. Regarding hyperthyroidism during pregnancy, the frequencies shared in the literature are very low - from $0.4 \%$ to $1.8 \%[14,15]$.

The aim of the present study is to analyze the population of pregnant women in Bulgaria regarding the main parameters that are relevant to their thyroid status - age, sequence of pregnancy, reproductive problems, family history of thyroid disease, body mass index.

\section{Study Design}

The study was conducted as a cross-sectional multicenter population-based and was realized from September 25 to November 6, 2019 in 10 regions of Bulgaria (Sofia and Sofia region - Samokov, Pirdop; Smolyan; Gotse Delchev; Gabrovo; Troyan-Apriltsi, Burgas, Stara Zagora, Pleven), including small towns and villages from each region or a total of 84 settlements. Regions with a known iodine deficiency in the past were included, such as Sofia-city, Sofia district, Smolyan, Gotse Delchev, Gabrovo, Troyan, as well as regions with iodine sufficiency in the past - Burgas, Stara Zagora, Pleven and their districts. The study was conducted with the assistance of 104 endocrinologists and gynecologists from selected areas. From their lists of registered pregnant women, a total of 630 people was invited to participate, with 547 (86.8\%) responding.

\section{Material}

We studied 547 pregnant women, mean $30 \pm 5$ years, median - 30 (18-47). The grouping by age of pregnant women is shown in Table 1.

Table 1. Distribution of screened pregnant women by age groups

\begin{tabular}{lll}
\hline Age (years) & Number & Percentage \\
\hline $18-22$ & 33 & 6.0 \\
$23-27$ & 115 & 21.0 \\
$28-32$ & 219 & 40.0 \\
$33-37$ & 128 & 23.4 \\
$38-42$ & 46 & 8.4 \\
$43-47$ & 6 & 1.1 \\
\hline
\end{tabular}

All participants signed an informed consent, approved by the local Ethics Commission at Sofiamed University Hospital, Sofia University "Saint Kliment Ohridski", and it was prepared in accordance with ethical standards according to the Helsinki-1964 Declaration and its later additions [16].

Each pregnant woman filled in a Questionnaire with the help of a specially designated medical person from the "face to face" team in order to correctly collect data on pregnancy history, intake of combined vitamins with minerals, vitamin D, other medications by type and doses, available thyroid or other diseases.

Pregnant women were admitted to the Screening at random without pre-selection, as $458 / 547(83.7 \%)$ of them took medicines. Most often these were magnesium, folic acid and iron $(58 \%)$, as well as some other drugs given to individual pregnant women in order to preserve the pregnancy and bring it to a successful conclusion - spasmolytics, progestins, anticoagulants and antiagregants. Substitution with Levothyroxine or thyrostatic treatment for a known thyroid disease was found in $77(14.1 \%)$ pregnant women. All participants were of Caucasians, with no evidence of liver, kidney disease, or malabsorption.

\section{Method}

After completing a personal Questionnaire, current weight and height were measured in each pregnant woman. The weight before pregnancy was recorded in the Questionnaire. The body mass index (BMI $-\mathrm{kg} / \mathrm{m}^{2}$ ) before pregnancy was calculated, as well as that at the time of screening, i.e. during pregnancy.

\subsection{Ultrasound Examination}

To determine the thyroid volume, an ultrasound examination was performed with a Digital Color Doppler Diagnostic Scanner, C5 Ex (Shenzhen Landwind Medical Industry, China)., The thyroid volume in $\mathrm{mL}$ was calculated according to the standard formula $[17,18]$.

\subsection{Labolatory Tests}

Laboratory analysis of all blood samples was performed in a Central laboratory on the day of blood sampling in the morning on an empty stomach. Serum was quantified on a Cobas e601: TSH analyzer with the ECLIA sandwich method (reference range 0.27-4.2 mIU / L); free thyroxine (FT4) with a competitive ECLIA method (reference limits 9.3-17.0 ng / L) and TPOAb with a competitive ECLIA method (reference limits<34 IU / mL).

\subsection{Statistical Analysis}

Analysis was performed using standard SPSS 13.0 for Windows: descriptive statistics (mean, medians, standard deviation), correlation analysis and analysis of variance (ANOVA, post-hoc test - with Bonferroni alpha correction), using parametrical and non-parametrical methods, including Chi-Square Test, Fisher's Exact Test, Kolmogorov-Smirnov, Shapiro-Wilk Tests, Levene's Test for Equality of Variances, Student's t-test, Kruskal-Wallis test and Mann-Whitney test. All quantitative variables were presented as mean with standard deviation, median or percentage (unless specified otherwise), $p$ values below 0.05 were accepted as statistically significant.

\section{Results}

\subsection{Role of Age}

As can be seen from Table 1, over $63 \%$ of the pregnant women we studied were in the age range of 28-37 years. TSH 
levels were found to be negatively correlated with age, rho=-0.116. $\mathrm{P}<0.07$ (Spearman's rho).

\subsection{Role of Pregnancy Sequence}

The sequence of pregnancy in the studied women and its relationship with the thyroid volume were analyzed. It was found that $83.3 \%$ of women had first and second pregnancies. The remaining $17 \%$ were divided into groups: with third pregnancy $(10.4 \%)$, fourth $(3.5 \%)$, fifth and sixth pregnancy $(1.8 \%)$. It turned out that in the first pregnancy the thyroid gland had the smallest volume, while in a sequence pregnancy the volume increased. When comparing the thyroid volume for the group of pregnant women with first pregnancy (n-245, $44.8 \%$ ) - 8.67 $\pm 2.23 \mathrm{~mL}$, median 8.35 (minimum 0.26, maximum 15.33) with the thyroid volume in the remaining $302(55.2 \%)$ pregnant women with sequence of pregnancy $9.15 \pm 2.85 \mathrm{~mL}$, median 8.96 (minimum 1.43 , maximum 23.04) we found a significant difference $(\mathrm{P}<0.01)$.

Additionally, a relationship between TSH level and pregnancy sequence and a significant negative correlation between the two parameters was found, $\mathrm{rho}^{=-0.099}, \mathrm{P}<0.02$ (non-parametric correlation analysis of Spearman's rho).

\subsection{Role of Reproductive Problems and Unfavorable Outcome}

Reproductive problems were reported by $119(21.8 \%)$ pregnant women, with a weak correlation with the level of TSH - rho=0.112, $\mathrm{P}<0.009$ (non-parametric correlation analysis of Spearman's rho). The Mann-Whitney test also showed significantly lower TSH levels $(\mathrm{P}<0.008)$ in pregnant women with reproductive problems compared to other studied women. An unfavorable outcome from a previous pregnancy was reported by $130(23.7 \%)$ of pregnant women, without any association with TSH levels.

\subsection{Role of Family History of Thyroid Disease}

Table 2. Distribution of 112 pregnant women with a family history of thyroid disease according to the current thyroid functional status.

\begin{tabular}{lll}
\hline Current thyroid Functional Status & Number & Percentage \\
\hline Subclinical Hypothyroidism & 26 & 23.2 \\
Clinical Hypothyroidism & 1 & 0.9 \\
Clinical Hyperthyroidism & 1 & 0.9 \\
Euthyroid State & 78 & 69.6 \\
Low FT4 & 6 & 5.4 \\
Total & 112 & 100.0 \\
\hline
\end{tabular}

Family burden of thyroid disease was found in $112(20.5 \%)$ pregnant women. It was important for us to investigate the current thyroid functional status in women who reported a family history of thyroid disease. The following Table 2 presents the functional thyroid characteristics of these 112 pregnant women with a family history. It turned out that currently $26(23.2 \%)$ pregnant women had hypothyroidism and two $(1.78 \%)$ had hyperthyroidism. Thus, in $25 \%$ of women with a family history of thyroid disease there were abnormalities in the thyroid function, as in $92.8 \%$ of cases this was hypothyroid condition and only in 7.2\% - hyperthyroid.

Additional analysis showed that there was a statistically significant relationship between thyroid function and family history, $\mathrm{P}<0.039$.

Thyroid disease was diagnosed in $77(14.1 \%)$ pregnant women before the current pregnancy. 76 (13.9\%) pregnant women received Levothyroxine replacement therapy and one pregnant woman $(0.18 \%)$ was treated with thyrostatic.

In the group of pregnant women we studied, the average level of TSH was $2.77 \pm 1.83 \mathrm{mIU} / \mathrm{L}$ (percentage $2.5^{\text {th }}-0.36$; $95^{\text {th }}-5.54 ; 97.5$ th -6.41$)$; Median 2.51 (0.02 - 24.15), percentiles $\left(2.5^{\text {th }}-0.36 ; 95^{\text {th }}-5.53 ; 97.5^{\text {th }}-6.29\right)$. The mean level of FT4 was $11,03 \pm 1,93 \mathrm{ng} / \mathrm{L}$ (percentage $2.5^{\text {th }}-7.88$; $95^{\text {th }}-14.54 ; 97.5^{\text {th }}-15.11$ ); Median 10.88 (percentage $2.5^{\text {th }}-$ $\left.7.88 ; 95^{\text {th }}-14.54 ; 97.5^{\text {th }}-15.11\right)$.

The examined pregnant women were distributed by trimesters as follows: first - $110(20.3 \%)$, second - 276 (50.4\%), third - $161(29.3 \%)$. As expected, TSH levels were lowest in the first trimester $(2.62 \pm 1.81 \mathrm{mIU} / \mathrm{L})$ and increased significantly in the second $(2.85 \pm 1.64 \mathrm{mIU} / \mathrm{L}), \mathrm{P}<0.004$. The level of TSH in the third trimester $(2.73 \pm 1.23 \mathrm{mIU} / \mathrm{L})$ was also significantly higher than in the first $(2.62 \pm 1.81 \mathrm{mIU} / \mathrm{L})$, $\mathrm{P}<0.006$. The level of FT4 in the first $(12.72 \pm 1.87 \mathrm{ng} / \mathrm{L})$ is significantly higher compared to the second $(10.94 \pm 1.79 \mathrm{ng} /$ $\mathrm{L})$ and third $(10.03 \pm 1.34 \mathrm{ng} / \mathrm{L})$ trimesters, $\mathrm{P}<0.0001$.

\subsection{Role of Body Mass Index (Before and During Pregnancy)}

The distribution of the BMI for the whole group of studied pregnant women (n-547) is presented in Table 3.

Table 3. Distribution of the studied pregnant women according to the body mass index.

\begin{tabular}{lll}
\hline BMI $\left(\mathrm{kg} / \mathbf{m}^{\mathbf{2}}\right)$ & Number & percentage \\
\hline$\leq 25 \mathrm{~kg} / \mathrm{m}^{2}$ & 383 & 70 \\
$25.00-29.99 \mathrm{~kg} / \mathrm{m}^{2}$ & 109 & 19.9 \\
$\geq 30 \mathrm{~kg} / \mathrm{m}^{2}$ & 55 & 10.1 \\
Total & 547 & 100.0 \\
\hline
\end{tabular}

The mean BMI before pregnancy for the whole cohort was $23.57 \pm 6.9 \mathrm{~kg} / \mathrm{m}^{2}$; median 22.15 (15.24 - 133.33), at the screening (i.e. during pregnancy) - 26.15 $\pm 7.28 \mathrm{~kg} / \mathrm{m}^{2}$; median 25.30 (16.51 - 147.22).

The mean weight before pregnancy for the whole group was $63.68 \pm 14.36 \mathrm{~kg}$, and at the screening i.e. during pregnancy was $70.60 \pm 14.50 \mathrm{~kg}$, the absolute difference being $6.92 \mathrm{~kg}$.

It turned out that $31 \%$ of pregnant women with normal weight before pregnancy gained weight and 30\% became overweight and $1 \%$ - obese. Pregnant women who were overweight before pregnancy in $2 / 3$ of the cases remained overweight, while $35 \%$ of them became obese. $98 \%$ of the pregnant women with obesity before pregnancy, remained obese and $1.8 \%$ became overweight, Table 4 .

This weight dynamics is significant, $\mathrm{P}<0.001$ (Fisher's Exact Test). 
Table 4. BMI before pregnancy and changes that occur during pregnancy are presented.

\begin{tabular}{|c|c|c|c|c|}
\hline BMI $\mathrm{kg} / \mathrm{m}^{2}$ & B. P.* number, (\%) & $\begin{array}{l}\text { D. P.** number, (\%) BMI } \leq 25 \\
\mathrm{~kg} / \mathrm{m}^{2}\end{array}$ & $\begin{array}{l}\text { D. P.** number, (\%) BMI } \\
25-29.99 \mathrm{~kg} / \mathrm{m}^{2}\end{array}$ & $\begin{array}{l}\text { D. P.** number, (\%) BMI } \\
\geq 30 \mathrm{~kg} / \mathrm{m}^{2}\end{array}$ \\
\hline$\leq 25$ & $383(70)$ & $264(68.9)$ & $114(29.8)$ & $5(1.3)$ \\
\hline $25-29.99$ & $109(19.9)$ & $1(0.9)$ & $69(63.3)$ & $39(35.8)$ \\
\hline$\geq 30$ & $55(10.1)$ & $0(0)$ & $1(1.8)$ & $54(98.2)$ \\
\hline Total & 547 & $265(48.5)$ & $184(33.6)$ & $98(17.9)$ \\
\hline
\end{tabular}

*B. P. - Before pregnancy **D. P. - During pregnancy.

By using Chi-Square Tests a significant relationship between obesity before pregnancy (BMI $\geq 30 \mathrm{~kg} / \mathrm{m}^{2}$ ) and current hypothyroid status in screened pregnant women was established. While in euthyroid pregnant women previous obesity was present in $8.6 \%(30 / 350)$, in hypothyroid pregnant women it was found in $12.7 \%$ (14 / 110), $\mathrm{P}<0.035$. In other words, BMI before pregnancy is a significant predictor of hypothyroidism, proven during pregnancy. At the same time, BMI during pregnancy did not show a relationship with the thyroid functional state.

The following Table 5 presents the BMI for the group of pregnant women with hypothyroidism (SCHT and CHT) and the group of pregnant women in euthyroid status, a total of 494 pregnant women. Pregnant women with euthyroid status with Levothyroxine replacement therapy were excluded. Regardless of the thyroid functional state before pregnancy, BMI increased during pregnancy.

Table 5. Comparison of BMI before and during pregnancy in the groups with hypothyroidism (clinical and subclinical) and in the euthyroid state.

\begin{tabular}{|c|c|c|c|c|c|c|}
\hline \multirow[b]{2}{*}{ Thyroid function } & \multicolumn{3}{|c|}{ BMI (kg/m2) before pregnancy } & \multicolumn{3}{|c|}{ BMI (kg/m2) during pregnancy } \\
\hline & BMI $\leq 25$ & BMI 25-29.9 & BMI $\geq \mathbf{3 0}$ & BMI $\leq 25$ & BMI 25-29.9 & BMI $\geq \mathbf{3 0}$ \\
\hline Hypothyroidism, n-144 / number, (\%) & $107(74.3)$ & $20(13.9)$ & $17(11.8)$ & $76(52.8)$ & $44(30.5)$ & $24(16.7)$ \\
\hline Euthyroidism, n-350 / number, (\%) & $243(69.4)$ & $77(22.0)$ & $30(8.6)$ & $175(50)$ & $115(32.8)$ & $60(17.2)$ \\
\hline Total, n-494 / number, (\%) & $350(70.8)$ & $97(19.6)$ & $47(9.6)$ & $251(50.8)$ & $159(32.2)$ & $84(17.0)$ \\
\hline
\end{tabular}

\section{Discussion}

The assessment of the risk of obstetric problems in pregnant women with SCHT varies. Many studies have noted that thyroid dysfunction (clinical or subclinical hypothyroidism or hyperthyroidism) is associated not only with obstetric problems for the mother, but also with problems related to the intellectual and physical development of the child [19-21]. However, there are studies that rule out the influence of subclinical hypothyroidism on the outcome of pregnancy and child development [22]. Derakhshan A. et al. (2020), based on a systematic review of data from 15 cohorts and a meta-analysis of 48145 mother-child pairs, concluded that adequate placental passage of maternal thyroid hormones is very important for normal fetal growth and development [24].

The distinctions are due to differences in the characteristics of the studied population - age, sequence of pregnancy, BMI, smoking. All of these population characteristics are important determinants of human chorionic gonadotropin (hCG) in early pregnancy [25]. This hormone is associated with early and strong thyroid changes during this period in response of the increased thyroid hormone needs [26]. Human chorionic gonadotropin is associated with risk of subclinical hyperthyroidism and hypothyroxinemia, but not with risk of subclinical hypothyroidism [27].

It is a well-known fact that the level of TSH increases with age, as does the frequency of TPOAb $(+)$ [28]. In developed countries, the incidence of thyroid diseases increases with the age of women. They are also very common in women of reproductive age, with clinically evident hypothyroidism and hyperthyroidism occurring in $3-4 \%$ of the population, and
SCHT reaching 10\% [28].

In Bulgaria, two national population screenings of people aged of 20-80 years (the first screening with 2402, the second with 2032 people) were conducted, with gender distribution according to the National Statistical Institute data from the respective years - December 2005 and February 2011 [29, 30]. Each screening also included thyroid pathology - hormonal level, thyroid antibodies, ultrasonography. Comparison of data from the two screenings showed an increase in the incidence of hypothyroidism from $6.33 \%$ in 2006 to $10.7 \%$ in 2012 . There is probably an increase in the absolute number of people with hypothyroidism, but the improved diagnosis is also very impressive. It turned out that in 2006 in $65 \%$ of cases there was newly diagnosed hypothyroidism, and in 2012 - only $44 \%$. There was a clear increase in the incidence of hypothyroidism with age $-20-44$ years $-3.9 \%, 45-59$ years $-6.7 \%, \geq 60$ years $10.9 \%$. According to the latest population data from 2012, the incidence of hyperthyroidism is $3.93 \%$ (known - $0.6 \%$ ), hypothyroidism - 10.7\% (known 6\%) [31].

The medical community has always been very interested in thyroid disease in the population of pregnant women due to its extreme importance in this period of a woman's life. Nathan N, Sullivan SD (2014) summarizes in their study that this is a very common disorder in women of reproductive age, with clinically evident hypothyroidism and hyperthyroidism occurring in $3-4 \%$ of the population, and SCHT reaching $10 \%$ [32]. In our material of 547 pregnant women it was found that $27.6 \%$ (n-151) of them had a disorder in thyroid function Subclinical hypothyroidism - 110 (20.1\%), Clinical hypothyroidism - 34 (6.2\%), Subclinical hyperthyroidism - 5 $(0.9 \%)$, Clinical hyperthyroidism $-2(0.4 \%)$. The goal of our project was to study the real status of urinary iodine 
concentration, TPOAb, thyroid hormones in Bulgarian population of pregnant women. It should be noted that optimal level of iodide was found in the study population, judging by the median urinary iodine concentration (mUIC) for the whole group of pregnant women (n-537) - $170 \mu \mathrm{g} / \mathrm{L}$ (95\% CI 161.00-177.00), which is a condition for the accuracy of the measured hormone levels in the studied population [33, 34]. A connection between thyroid dysfunction and the influence of additional factors, such as age, family thyroid burden, weight, which were subject of the present study, was also sought.

We demonstrated a significant correlation of TSH with age in pregnant women, similar to that of the general population. As can be seen in Table 1, over $63 \%$ of the surveyed pregnant women were between the ages of $28-37$. Only $27 \%$ of pregnant women were in the 20-27 age range, while the remaining Bulgarian women became pregnant when they were older. This is a very important issue due to the relationship between obstetric complications and thyroid function, as found in a meta-analysis of P. M. Sheehan et al. (2015), who showed a slight increase in preterm birth in SCHT and a significant increase in CHT, $\mathrm{P}<0.001$ [35].

On the other hand, fertility problems are also closely related to the functional status of the thyroid gland. The authors of the Danish population study Feldthusen A-D. et al (2015) on more than 11000 pregnant women with SCHT concluded that as TSH rises, fewer children are born and fewer pregnancies occur. At a higher level of TPOAb $(+)$ - a smaller number of children are born. SCHT is associated with an older age for the birth of the first child, with the risk of having no children or not becoming pregnant [36].

In addition, two facts should be noted. The sequence of pregnancies is significantly negatively related to the level of TSH $(\mathrm{P}<0.02)$, and the family history in $25 \%$ of pregnant women is an important factor. In these pregnant women in $92.8 \%$ of cases there is a hypothyroid condition and only in $7.2 \%$ - hyperthyroid. These facts mean that these groups of pregnant women must be tested for thyroid disorders.

Body mass index (BMI) is one of the main characteristics of the population related to the serum parameters of the thyroid gland $[37,38]$. BMI is associated with TSH and FT4 during pregnancy. There are authors who found that the $95^{\text {th }}$ percentile of TSH is $3.50 \mathrm{mU} / \mathrm{L}$ among women with a BMI of $30 \mathrm{~kg} / \mathrm{m}^{2}$ versus $2.86 \mathrm{mU} / \mathrm{L}$ among women with a BMI of 20 $\mathrm{kg} / \mathrm{m}^{2}$ [36]. This is exactly what we specified in the ATA Recommendations from 2011 - to conduct screening for thyroid disease in obese pregnant women [4].

In our material, this connection has been proven unequivocally. While in euthyroid pregnant women previous obesity was present in $8.6 \%(30 / 350)$, in hypothyroid pregnant women it was found in $12.7 \%(14 / 110), \mathrm{P}<0.035$ (Fisher's Exact Test). In other words, BMI before pregnancy is a significant predictor of hypothyroidism, proven during pregnancy. At the same time, BMI during pregnancy did not show a relationship with the thyroid functional state.

It was found that the BMI on average for the group examined before pregnancy was $23.36 \pm 5.05 \mathrm{~kg} / \mathrm{m}^{2}$, median 22.06 (minimum 15.24, maximum 63.25), and during pregnancy at the time of screening $-25.91 \pm 5.11 \mathrm{~kg} / \mathrm{m}^{2}$, median 25.26 (minimum 16.51, maximum 63.25), (T-6.793, $\mathrm{P}<0.001)$. The mean increase in BMI for the two study periods was $2.46 \pm 2.05$ $\mathrm{kg} / \mathrm{m}^{2}$, median 2.09 (minimum - 3.29, maximum - 13.89). The additional McNemar-Bowker test showed a significant change in BMI at the time of screening compared to BMI before pregnancy, $\mathrm{P}<0.014$. This $\mathrm{McNemar-Bowker}$ test actually shows that the observed changes are not accidental and are expected to be similar in the sampled population.

\section{Conclusion}

The preliminary in-depth study and presentation of the characteristics of the studied Bulgarian population of pregnant women is the basis for a proper assessment of the condition of the thyroid gland. The role of age, sequence of pregnancy, family history of thyroid disease, reproductive problems, body mass index is indisputable. Pregnant women over 30 years of age who are overweight or obese and have a family history of thyroid disease, sequent pregnancy or reproductive problems should be examined in order to determine their thyroid status. An extremely important first step should be verbal screening, which will help us find suitable pregnant women for this screening.

These conclusions need to be confirmed in a follow-up study because this project was a cross-sectional study. More long-term follow-up studies are needed to investigate better the influence of certain factors on thyroid function during pregnancy and especially after birth. The postpartum period is also extremely vulnerable to thyroid autoimmunity, in which a rise is usually observed. This early postpartum period should be strictly monitored to obtain very useful data about the long-term role of the studied factors.

\section{Conflicts of Interests}

All the authors do not have any possible conflicts of interest.

\section{Acknowledgements}

The authors thank the endocrinologists and obstetrician/gynecologists who provided local support: V. Jotova (Troyan), S. Dimitrova (Gabrovo), Anchev (Gabrovo), Mitev (Gabrovo), A. Popov (Goce Delchev), A. Andreev (Samokov), E. Apostolova (Smolyan), M. Hubshev (Smolyan), S. Dimitrov (Pirdop), R. Naumovska (Pleven), M. Manuelyan (Burgas), K. Kirovakov (Burgas), T. Gabrovska (Burgas), K. Venkova (Sofia), M. Angelova (Stara Zagora), R. Velev (Sofia), I. Sigridov (Sofia), B. Bogoslovova (Sofia)... total 104 specialists in the country. Technical support: T. Kornilova (Sofia), Z. Metodieva (Sofia), J. Georgieva (Sofia), H. Atanasova (Burgas), I. Ilieva (Stara Zagora).

This work was supported by grants from the Bulgarian Society of Endocrinology as part of the National Epidemiological Program for Pregnant Women in Bulgaria 2019. 


\section{References}

[1] Valdes S, Maldonado-Araque C, Lago-Sampedro A, Lillo JA, Garcia-Fuentes E, Perez-Valero V, et al. (2017). Population-Based National Prevalence of Thyroid Dysfunction in Spain and Associated Factors: Di@bet.es Study. Thyroid. 27 (2): 156-66.

[2] Lazarus J, Brown RS, Daumerie C, Hubalewska-Dydejczyk A, Negro R, Vaidya B. (2014). 2014 European thyroid association guidelines for the management of subclinical hypothyroidism in pregnancy and in children. Eur Thyroid J. 3 (2): 76-94.

[3] De Groot L, Abalovich M, Alexander EK, Amino N, Barbour L, Cobin RH, Eastman CJ, Lazarus JH, Luton D, Mandel SJ, Mestman J, Rovet J, Sullivan S. (2012). Management of thyroid dysfunction during pregnancy and postpartum: an Endocrine Society clinical practice guideline. J Clin Endocrinol Metab. 97 (8): 2543-2565.

[4] Stagnaro-Green A, Abalovich M, Alexander E, Azizi F, Mestman J, Negro R, Nixon A, Pearce EN, Soldin OP, Sullivan S, Wiersinga W. (2011). American Thyroid Association Taskforce on Thyroid Disease During Pregnancy and Postpartum. Guidelines of the American Thyroid Association for the diagnosis and management of thyroid disease during pregnancy and postpartum. Thyroid 21 (10): 1081-1125.

[5] Chan S, Boelaert K. (2015). Optimal management of hypothyroidism, hypothyroxinaemia and euthyroid TPO antibody positivity preconception and in pregnancy. Clin Endocrinol (Oxf). 82 (3): 313-326.

[6] Taylor PN, Muller I, Nana M, Velasco I, Lazarus JH. Indications for treatment of subclinical hypothyroidism and isolated hypothyroxinaemia in pregnancy. (2020). Best Pract Res Clin Endocrinol Metab. 34 (4): 101436. doi: 10.1016/j.beem.2020.101436.

[7] Abalovich M, Alcaraz G, Kleiman-Rubinsztein J, Pavlove MM, Cornelio C, Levalle O, Gutierrez S. (2010). The relationship of preconception thyrotropin levels to requirements for increasing the levothyroxine dose during pregnancy in women with primary hypothyroidism. Thyroid 20: 1175-1178.

[8] Lazarus JH. (2011). Thyroid function in pregnancy. Br Med Bull 97: 137-148.

[9] Moreno-Reyes R, Glinoer D, Van Oyen H, Vandevijvere S. (2013). High prevalence of thyroid disorders in pregnant women in a mildly iodine-deficient country: a population-based study. J Clin Endocrinol Metab 98: 36943701 .

[10] Aguayo A, Grau G, Vela A, Aniel-Quiroga A, Espada M, Martul P, Castaño L, Rica IJ. (2013). Urinary iodine and thyroid function in a population of healthy pregnant women in the North of Spain. Trace Elem Med Biol 27: 302-306.

[11] Alkafajei A, Amarin Z, Alazaizeh W, Khader Y, Marji M. (2012). Prevalence and risk factors for hypothyroidism in Jordanian women: comparison between different reference ranges. East Med Health J 18: 2.

[12] Medici M, de Rijke YB, Peeters RP, Visser W, de Muinck Keizer-Schrama SM, Jaddoe VV, Hofman A, Hooijkaas H, Steegers EA, Tiemeier H. (2012). Maternal early pregnancy and newborn thyroid hormone parameters: the generation $\mathrm{R}$ study. J Clin Endocrinol Metab. 97 (2): 646-652.

[13] Li C, Shan Z, Mao J, Wang W, Xie X, Zhou W, Li C, Xu B, Bi L, Meng T, Du J, Zhang S, Gao Z, Zhang X, Yang L, Fan C, Teng W. (2014). Assessment of thyroid function during first-trimester pregnancy: what is the rational upper limit of serum TSH during the first trimester in Chinese pregnant women? J Clin Endocrinol Metab. 99 (1): 73-79.

[14] Marx H, Amin P, Lazarus JH. (2008). Hyperthyroidism and pregnancy. BMJ 336: 663-667.

[15] Weiwei Wang, Weiping Teng, Zhongyan Shan, Sen Wang, Jianxin Li, Lin Zhu, Jin Zhou, Jinyuan Mao, Xiaohui Yu, Jia Li, Yanyan Chen, Haibo Xue, Chenling Fan, Hong Wang, Hongmei Zhang, Chenyang Li, Weiwei Zhou, Bo Gao, Tao Shang, Jiaren Zhou, Bin Ding, Ying Ma, Ying Wu, Hui Xu, Wei Liu. (2011). The prevalence of thyroid disorders during early pregnancy in China: the benefits of universal screening in the first trimester of pregnancy. Eur J Endocrinol 164: 263-268.

[16] World Medical Association (2013). "Declaration of Helsinki: Ethical Principles for Medical Research Involving Human Subjects". JAMA. 310 (20): 2191-2194. doi: 10.1001/jama.2013.28105.

[17] Brunn J, Block U, Ruf G, Bos I, Kunze WP, Scriba PC. (1981). Volumetric analysis of thyroid lobes by real-time ultrasound. Dtsch Med Wochenschr. 106: 1338-1340.

[18] Zimmermann MB, Hess S. Y, de Benoist L. M. B, Delange F, Braverman L. E, Fujieda K, Ito Y, Jooste P. L, Moos K, Jooste P. L, Pearce E. N, Pretell E. A, Shishiba Y.(2004). New reference values for thyroid volume by ultrasound in iodine sufficient school children: a World Health Organization/Nutrition for Health and Development Iodine Deficiency Study Group Report. Am J Clin Nutr 79: 231237.

[19] Korevaar T. I. M, Medici M, Visser TJ, Peeters RP. (2017). Thyroid disease in pregnancy: new insights in diagnosis and clinical management. Nat Rev Endocrinol. 13 (10): 610-622.

[20] Negro R. (2019). Levothyroxine before conception in women with thyroid antibodies: a step forward in the management of thyroid disease in pregnancy. Thyroid Research 12: 5. https://doi.org/10.1186/s13044-019-0066-0.

[21] Rao M, Zeng Z, Zhao S. and Tang L. (2018). Effect of levothyroxine supplementation on pregnancy outcomes in women with subclinical hypothyroidism and thyroid autoimmuneity undergoing in vitro fertilization / intracytoplasmic sperm injection: an updated meta-analysis of randomized controlled trials. Reproductive Biology and Endocrinology 16: https://doi.org/10.1186/s12958-018-0410-6.

[22] Casey B. M, Thom E. A, Peaceman A. M, Varner M. W, Sorokin Y, Hirtz D. G, Reddy U. M, Wapner R. J, Thorp Jr. J. M, Saade G, Tita A. TN, Rouse D. J, Sibai B, Iams J. D, Mercer B. M, Tolosa J, Caritis S. N, Van Dorsten J. P. (2017). Treatment of Subclinical Hypothyroidism or Hypothyroxinemia in Pregnancy. N Engl J Med 376: 815-825. DOI: 10.1056/NEJMoa1606205.

[23] Korevaar T. I. M, Derakhshan A, Taylor P. N, Meima M, Chen L, Bliddal S. et al. (2019). Association of Thyroid Function Test Abnormalities and Thyroid Autoimmunity With Preterm Birth. JAMA. 322 (7): 632-641. 
[24] Derakhshan A, Peeters RP, Taylor PN, Bliddal S, Carty DM, Meems M, Vaidya B, et al. (2020). Association of maternal thyroid function with birthweight: a systematic review and individual-participant data meta-analysis. Lancet Diabetes $\begin{array}{llll}\text { Endocrinol. } & 8 & (6): & 501-510 .\end{array}$ $10.1016 /$ S2213-8587(20)30061-9.

[25] Korevaar T. I. M, Steegers E. A. P, Chaker L, Medici M, Jaddoe V. W. V, Visser T. J, de Rijke Y. B. and Peeters R. P. (2017). Thyroid Function and Premature Delivery in TPO Antibody Negative Women: The Added Value of hCG. J Clin Endocrinol Metab 102: 3360-3367.

[26] Korevaar T. I. M, Steegers EA, de Rijke YB, Schalekamp-Timmermans S, Visser WE, Hofman A, Jaddoe VW, Tiemeier H, Visser TJ, Medici M, Peeters RP. (2015). Reference ranges and determinants of total hCG levels during pregnancy: the Generation R Study. Eur J Epidemiol. 30 (9): $1057-1066$.

[27] Korevaar T. I. M, de Rijke Y. B, Chaker L, Medici M, Jaddoe V. W. V, Steegers E. A. P, Visser T, Peeters R. P. (2017). Stimulation of Thyroid Function by Human Chorionic Gonadotropin During Pregnancy: A Risk Factor for Thyroid Disease and a Mechanism for Known Risk Factors. Thyroid; 27 (3): 440-450.

[28] Surks M. I. and Hollowell J. G. (2007). Age-specific distribution of serum thyrotropin and antithyroid antibodies in the U.S. population: implications for the prevalence of subclinical hypothyroidism. Journal of Clinical Endocrinology and Metabolism; 92, 12, 4575-4582.

[29] NSI. The population of Bulgarian Republic. National Statistical Institute. 2005. Available at: http://www.nsi.bg/Population/Population.htm.

[30] NSI. $17^{\text {th }}$ National population census in Bulgaria. National Statistical Institute. 2011. Available at: http://censusresults.nsi.bg/Census/Reports/2/2/R1.aspx.

[31] Borissova A-M, Shinkov A, Vlahov J, Dakovska L, Todorov
T. (2012). Screening for endocrine diseases in the Bulgarian population $\geq 20$ years of age (preliminary data). $15^{\text {th }}$ National Symposium on Endocrinology, April 19-21, 2012, Plovdiv, Bulgaria.

[32] Nathan N, Sullivan SD. (2014). Thyroid disorders during pregnancy. Endocrinol Metab Clin North Am. 43: 573-597.

[33] Borissova Anna-Maria I., Ivanova Ludmila B, Trifonova Boyana C, Dakovska Lilia N, Mihailova Eugenia N, Vukov Mircho I. (2020). Urine iodine concentration, TPOAb, thyroid hormones in pregnant Bulgarian women - results of a screening study. Endocrinologia, 25 (3): 175-189.

[34] Borissova A-M, Trifonova B, Ivanova L, Dakovska L, Mihailova E, Vukov M. (2020). Frequency and characteristics of thyroid dysfunction in pregnant women - screening of 547 women in Bulgaria. Medical \& Clinical Research, Volume 5 | Issue 9 | 244-250.

[35] Sheehan PM, Nankervis A, Araujo E. Júnior, Da Silva Costa F. (2015). Maternal Thyroid Disease and Preterm Birth: Systematic Review and Meta-Analysis. J Clin Endocrinol Metab 100: 4325-4331.

[36] Feldthusen A-D, Pedersen PL, Larsen J, Kristensen TT, Ellervik C, Kvetny J. (2015). Impaired Fertility Associated with Subclinical Hypothyroidism and Thyroid Autoimmunity: The Danish General Suburban Population Study. Journal of Pregnancy, Article ID 132718, 6 pages http://dx.doi.org/10.1155/2015/132718.

[37] Männistö T, Surcel HM, Ruokonen A, Vääräsmäki M, Pouta A, Bloigu A, Järvelin MR, Hartikainen AL, Suvanto E. (2011). Early pregnancy reference intervals of thyroid hormone concentrations in a thyroid antibody-negative pregnant population. Thyroid 21: 291-298.

[38] Pop VJ, Biondi B, Wijnen HA, Kuppens SM, Lvader H. (2013). Maternal thyroid parameters, body mass index and subsequent weight gain during pregnancy in healthy euthyroid women. Clin Endocrinol (Oxf) 79: 577-583. 